OPEN ACCESS

Edited by:

Gabriele Spoletini,

Agostino Gemelli University Polyclinic

(IRCCS), Italy

Reviewed by:

Fabrizio Romano,

University of Milano-Bicocca, Italy

Mikel Prieto,

Cruces University Hospital, Spain

*Correspondence:

Jinhang Zhang

george202110@163.com

†These authors have contributed equally to this work and share first authorship

Specialty section:

This article was submitted to Surgical Oncology, a section of the journal

Frontiers in Surgery

Received: 07 November 2021

Accepted: 13 January 2022

Published: 09 February 2022

Citation:

Lin Y, Xu J, Hong J, Si Y, He Y and Zhang J (2022) Prognostic Impact of Surgical Margin in Hepatectomy on

Patients With Hepatocellular

Carcinoma: A Meta-Analysis of Observational Studies.

Front. Surg. 9:810479.

doi: $10.3389 /$ fsurg.2022.810479

\section{Prognostic Impact of Surgical Margin in Hepatectomy on Patients With Hepatocellular Carcinoma: A Meta-Analysis of Observational Studies}

\author{
Yeting $\mathrm{Lin}^{1+}$, Jiaxuan $\mathrm{Xu}^{2+}$, Jiaze Hong ${ }^{2}$, Yuexiu $\mathrm{Si}^{3}$, Yujing $\mathrm{He}^{2}$ and Jinhang Zhang ${ }^{4 *}$ \\ ${ }^{1}$ Anesthesiology Department, Ningbo Yinzhou No. 2 Hospital, Ningbo, China, ${ }^{2}$ The Second Clinical Medical College, \\ Zhejiang Chinese Medical University, Hangzhou, China, ${ }^{3}$ School of Basic Medical Sciences, Zhejiang Chinese Medical \\ University, Hangzhou, China, ${ }^{4}$ Surgery Department, Fenghua Hospital of Traditional Chinese Medicine, Ningbo, China
}

Objective: This study aims to comprehensively evaluate the prognostic impact of the surgical margin in hepatectomy on patients diagnosed with hepatocellular carcinoma ( $\mathrm{HCC})$.

Methods: A comprehensive and systematic search for eligible articles published in English before July 2021 was conducted across PubMed, Cochrane Library, Web of Science, and Embase electronic databases. The overall survival (OS) and disease-free survival (DFS) were the primary endpoints.

Results: In total, 37 observational studies with 12,295 cases were included in this meta-analysis. The results revealed that a wide surgical margin $(\geq 1 \mathrm{~cm})$ was associated with better OS (hazard ration (HR), 0.70; 95\% confidence interval $(\mathrm{Cl}), 0.63-0.77)$ and DFS (HR, 0.66; 95\% Cl, 0.61-0.71) compared to a narrow surgical margin $(<1 \mathrm{~cm})$. Subgroup analyses were conducted based on median follow-up time, gender, country, hepatitis B surface antigen ( $\mathrm{HBsAg}$ ) status, tumor number, and liver cirrhosis. The prognostic benefit of a wide surgical margin was consistent in most subgroups, however, analysis of studies from Western countries showed that margin width was not associated with prognosis.

Conclusion: In summary, a surgical margin wider than $1 \mathrm{~cm}$ prolongs the long-term prognosis of HCC patients compared to a surgical margin narrower than $1 \mathrm{~cm}$.

Keywords: hepatocellular carcinoma, hepatectomy, surgical margin, prognosis, meta-analysis

\section{INTRODUCTION}

Although hepatocellular carcinoma (HCC) has the $5^{\text {th }}$ highest incidence across the globe, it is currently the $3^{\text {rd }}$ leading cause of cancer-related deaths $(1,2)$. So far, liver transplantation, hepatic resection and radiofrequency ablation are the few treatment strategies for HCC. Although hepatectomy is the first-line therapeutic intervention, the prognosis of patients is unsatisfactory due to the high risk of recurrence ( $70 \%$ in the $5^{\text {th }}$ year after surgery) and metastasis (3). 
The long-term prognosis of patients with HCC is influenced by several factors, among them, liver cirrhosis is a main factor, and the surgical margin is considered a potential prognostic factor $(4,5)$. Curative hepatectomy is complete resection of all visible tumors without residual tumor cells at the resection margin (6). As such, an adequate resection margin is vital in preventing tumor recurrence (7). Nonetheless, minimizing the removal of the non-malignant parenchyma tissue and protecting the residual liver of liver resection is necessary for many HCC patients with liver cirrhosis or other liver diseases. This is because the capacity for liver regeneration is impaired among these patients and excessive liver tissue removal leads to severe consequences including liver failure $(8,9)$. Thus, controversies on the width of the surgical margin have been reported under the premise of R0 resection. Many studies reveal that the width of the resection margin narrower than $1 \mathrm{~cm}$ is a risk factor for the long-term prognosis of HCC patients after surgery $(4,10)$. Nevertheless, a number of articles found that a wide surgical margin did not improve the prognosis of HCC patients after hepatectomy $(11,12)$.

Therefore, this meta-analysis seeks to assess the correlation between surgical margins (a surgical margin wider than $1 \mathrm{~cm}$; a surgical margin narrower than $1 \mathrm{~cm}$ ) and long-term prognosis of HCC patients after hepatectomy.

\section{METHODS}

\section{Literature Search Strategy}

This meta-analysis adhered to the guidelines from the Preferred Reporting Items for Systematic Review and Meta-Analysis (13). A comprehensive and systematic literature search for articles published in English before July 2021 was conducted in four online electronic databases including PubMed, Cochrane Library, Web of Science, and Embase. The search terminologies included: "Hepatocellular Carcinoma" OR "Liver Cell Carcinomas" OR "Hepatoma” OR "HCC” AND "Resection Margin" OR "Surgical Margin" OR "Margin Width." Besides, reference lists of all retrieved papers were inspected to identify potentially eligible but uncaptured literature in the primary search.

\section{Inclusion Criteria}

Studies were included if they met the following criteria: (1) The cancer type was primary HCC and hepatectomy was performed on patients; (2) Patients received different surgical margins in the study (a wide surgical margin, $\geq 1 \mathrm{~cm}$ ) and control (a narrow surgical margin, $<1 \mathrm{~cm}$ ) groups; (3) The study was original, including retrospective and prospective observational studies (OBS); (4) Extractable outcomes were in the studies.

\footnotetext{
Abbreviations: HCC, hepatocellular carcinoma; OS, overall survival; DFS, diseasefree survival; HR, hazard ratio; CI, confidence interval; HBsAg, hepatitis B surface antigen; OBS, observational study; AFP, alpha-fetoprotein; NOS, NewcastleOttawa Scale; HBV, hepatitis B virus; PSM, propensity score matching; MVI, microvascular invasion.
}

\section{Exclusion Criteria}

The exclusion criteria for this meta-analysis included: (1) HCC was recurrent; (2) The patients received palliative hepatectomy or had extrahepatic metastases; (3) The study did not divide the study group and the control group into larger than $1 \mathrm{~cm}$ and smaller than $1 \mathrm{~cm}$; (4) Duplicate article or repeat analyses using similar data.

\section{Data Extraction and Quality Evaluation}

Data extracted from eligible studies included study characteristics (author, country, publication year, study design, median followup time, and mentioned outcome measures), demographic data of patients (age, gender, and the number of patients), and clinicopathological features (liver cirrhosis, virus status, tumor number and size, and serum alpha-fetoprotein (AFP), and survival outcomes.

The quality of incorporated OBSs was evaluated using the Newcastle-Ottawa Scale (NOS) based on three aspects i.e., patient selection, comparability of groups, and outcome evaluation. The scores of papers $>6$ were considered high-quality.

\section{Statistical Analysis}

To evaluate the relationship between surgical margins and HCC prognosis, the overall survival (OS) and disease-free survival (DFS) in the wide surgical margin group vs. the narrow surgical margin group was compared using a pooled hazard ratio (HR) with its corresponding 95\% confidence interval (CI). The degree of heterogeneity across included literature was assessed using the $\mathrm{I}^{2}$ statistic. Considering the potential heterogeneity, randomeffect model was applied to all analyses. To assess the robustness of conclusions, a sensitivity analysis was conducted. $P<0.05$ was considered statistically significant.

\section{RESULTS}

\section{Data Collection and Characteristics}

A total of 6,864 records were initially identified by the literature search. Out of these, 4,743 records were excluded because of duplication, and 2,050 records were eliminated after evaluating their titles or abstracts. The remaining 71 records were carefully inspected by full-text reading. Finally, 37 articles $(4,5,7,10-12$, 14-44) were included. The comprehensive search and selection process is shown in (Figure 1).

The comprehensive characteristics of the included studies are summarized in (Table 1-1). The included articles were published between 1993 and 2021. A total of 12,295 patients from Western and Asian countries were enrolled in 37 OBSs; two studies of these were prospective, while the rest were retrospective. The majority of articles were from Asia, with China representing the most (24 articles). The demographic and clinicopathological characteristics of patients are presented in (Table 1-2). Based on a qualitative assessment by NOS criteria, the results revealed that all included OBSs were of higher quality (Supplementary Table 1). 


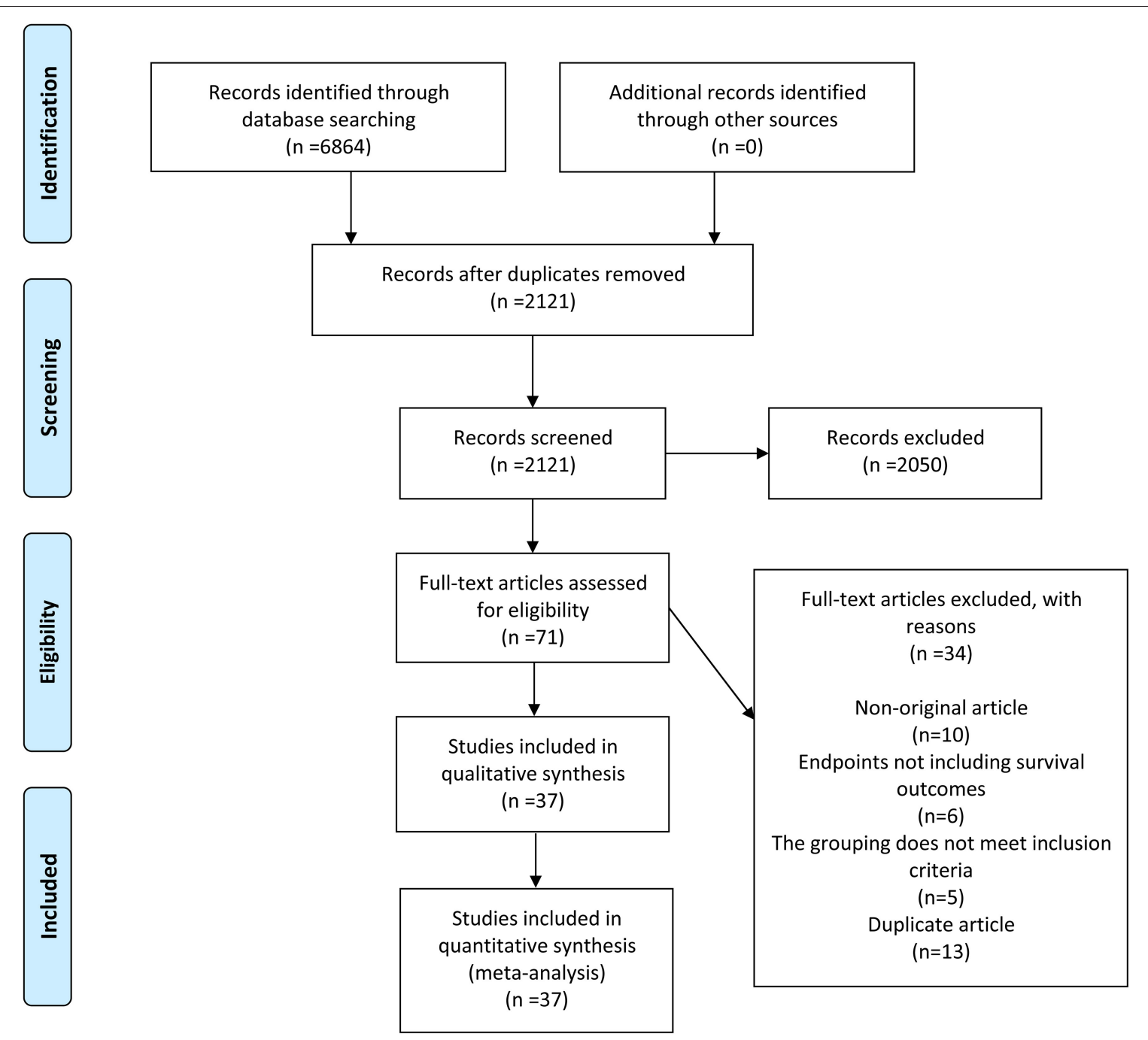

FIGURE 1 | A schematic flow for selecting the articles included in the meta-analysis.

\section{Correlation Between Surgical Margin and OS}

A total of 28 studies reported on OS outcomes and pooling analysis of these data revealed that a wide surgical margin is associated with better OS (HR, 0.70; 95\% CI, 0.63-0.77) compared to a narrow surgical margin (Figure 2). Subgroups analyses were conducted to explore the potential factors that might affect the impact of the surgical margin on the prognosis (Table 2). This was based on the reported median follow-up time. The studies were divided into 3-year OS and 5-year OS subgroups. The result showed that patients who received a wide resection margin had better mid-and long-term prognosis than those who received a narrow resection margin. Moreover, the gender factor in the subgroups was analyzed and the findings revealed that a narrow surgical margin was a risk factor for OS of patients regardless of men and women. For patients from China or Non-Chinese Asian countries, a wide resection margin was associated with better OS than a narrow resection margin. However, a pooled analysis of three studies from western countries showed that margin width was not associated with prognosis. Additionally, the wide surgical margin group obtained greater OS than that of the narrow surgical margin group in subgroups of hepatitis B surface antigen status (HBsAg) positive/negative and single/multiple tumors.

\section{Correlation Between Surgical Margin and DFS}

A pooled analysis of DFS data from 27 studies including 9,443 patients revealed that a wide surgical margin was related to better DFS (HR, 0.66; 95\% CI, 0.61-0.71) (Figure 3). Further, subgroup analyses were performed based on reported median followup time (3-year DFS/5-year DFS), gender (male/female), country (China/Non-Chinese Asian countries/Western countries), HBsAg status (positive/negative), tumor number 
TABLE 1-1 | Characteristics of all the studies included in the meta-analysis.

\begin{tabular}{|c|c|c|c|c|c|c|c|}
\hline \multirow[t]{2}{*}{ Author } & \multirow[t]{2}{*}{ Year } & \multirow[t]{2}{*}{ Country } & \multicolumn{2}{|c|}{ Number of patients } & \multirow{2}{*}{$\begin{array}{l}\text { Median follow-up } \\
\text { (months) }\end{array}$} & \multirow[t]{2}{*}{ Study design } & \multirow{2}{*}{$\begin{array}{l}\text { Survival } \\
\text { outcomes }\end{array}$} \\
\hline & & & $\begin{array}{l}\text { Wide resection } \\
\text { margin }(>1 \mathrm{~cm})\end{array}$ & $\begin{array}{c}\text { Narrow resection } \\
\text { margin }(<1 \mathrm{~cm})\end{array}$ & & & \\
\hline Belli & 2011 & Italy & 56 & 9 & 29.0 & Retrospective & DFS \\
\hline Chang & 2012 & China & & 478 & 29.5 & Retrospective & DFS \\
\hline Chen & 2003 & China & 174 & 68 & 11.8 & Retrospective & OS \\
\hline Chen & 2015 & China & 114 & 82 & NA & Retrospective & OS \\
\hline Chen & 2021 & China & 176 & 238 & $>60.0$ & Retrospective & OS \\
\hline Dong & 2016 & China & 351 & 235 & 46.8 & Retrospective & DFS \\
\hline Han & 2019 & China & 302 & 147 & 56.3 & Retrospective & OS, DFS \\
\hline Hirokawa & 2014 & Japan & 10 & 10 & 46.0 & Retrospective & DFS \\
\hline Hsiao & 2017 & China & 154 & 67 & NA & Retrospective & OS \\
\hline Huang & 2013 & China & 528 & 512 & 42.0 & Retrospective & OS, DFS \\
\hline Huang & 2015 & China & 71 & 159 & 72.0 & Retrospective & OS, DFS \\
\hline Laurent & 2005 & France & 61 & 41 & 23.0 & Retrospective & OS, DFS \\
\hline Lee & 1996 & China & 38 & 10 & $>60.0$ & Retrospective & OS \\
\hline Lee & 2007 & Korea & 44 & 56 & 31.0 & Retrospective & OS, DFS \\
\hline Lee & 2012 & China & 142 & 156 & 73.0 & Retrospective & OS, DFS \\
\hline Lee & 2018 & Korea & 186 & 233 & 37.5 & Retrospective & OS, DFS \\
\hline Lee & 2019 & China & 143 & 391 & 66.3 & Retrospective & OS, DFS \\
\hline Lise & 1998 & Italy & 72 & 15 & 29.0 & Retrospective & OS, DFS \\
\hline Liu & 2016 & China & 186 & 37 & 26.1 & Retrospective & DFS \\
\hline Liu & 2020 & China & 134 & 106 & 55.2 & Retrospective & OS, DFS \\
\hline Park & 2018 & Korea & 61 & 31 & 28.0 & Retrospective & OS, DFS \\
\hline Poon & 2000 & China & 138 & 150 & 27.0 & Prospective & OS, DFS \\
\hline Sasaki & 2006 & Japan & 176 & 241 & $>120.0$ & Retrospective & DFS \\
\hline Shi & 2019 & China & 177 & 99 & 44.0 & Retrospective & OS, DFS \\
\hline Shimada & 2008 & Japan & 32 & 85 & 62.0 & Retrospective & OS \\
\hline Shin & 2018 & Korea & 55 & 61 & 66.7 & Retrospective & DFS \\
\hline Su & 2021 & China & 45 & 114 & 61.2 & Retrospective & OS, DFS \\
\hline Takano & 2000 & Japan & 244 & 56 & NA & Retrospective & OS \\
\hline Torii & 1993 & Japan & 25 & 34 & 25.0 & Retrospective & OS \\
\hline Tsilimigras & 2020 & Multicenter & 78 & 326 & 28.5 & Retrospective & OS, DFS \\
\hline Wang & 2010 & China & 404 & 34 & 21.0 & Retrospective & OS \\
\hline Yang & 2014 & China & 126 & 959 & NA & Retrospective & OS, DFS \\
\hline Zeng & 2020 & China & 155 & 544 & NA & Retrospective & OS, DFS \\
\hline Zhang & 2014 & China & 216 & 86 & 26.0 & Prospective & DFS \\
\hline Zhang & 2021 & China & 305 & 120 & 26.0 & Retrospective & DFS \\
\hline Zhou & 2020 & China & 92 & 217 & NA & Retrospective & OS, DFS \\
\hline Zhou & 2021 & China & 325 & 492 & NA & Retrospective & OS \\
\hline
\end{tabular}

OS, overall survival; DFS, disease-free survival; NA, not available.

(single/multiple), liver cirrhosis (patients with/without). As a consequence, a wide surgical margin provided patients with better DFS compared to a narrow surgical margin (Table 2).

\section{Sensitivity Analysis}

After careful selection of studies in sequence, sensitivity analysis outcomes confirmed the excellent robustness of the conclusion that a wide surgical margin could benefit the OS and DFS of patients (Supplementary Figures 1, 2).

\section{DISCUSSION}

The findings of this meta-analysis revealed that surgical margins correlate with the prognosis of HCC patients; besides, a wide surgical margin $(\geq 1 \mathrm{~cm})$ could improve long-term prognosis compared to a narrow surgical margin $(<1 \mathrm{~cm})$. This is in line with the results reported in previous articles $(39,40)$. Through subgroups analyses, we found that the above outcome showed a similar phenomenon in different subgroups except for studies from Western countries. In this analysis, a wide surgical margin 
TABLE 1-2 | Characteristics of all the studies included in the meta-analysis.

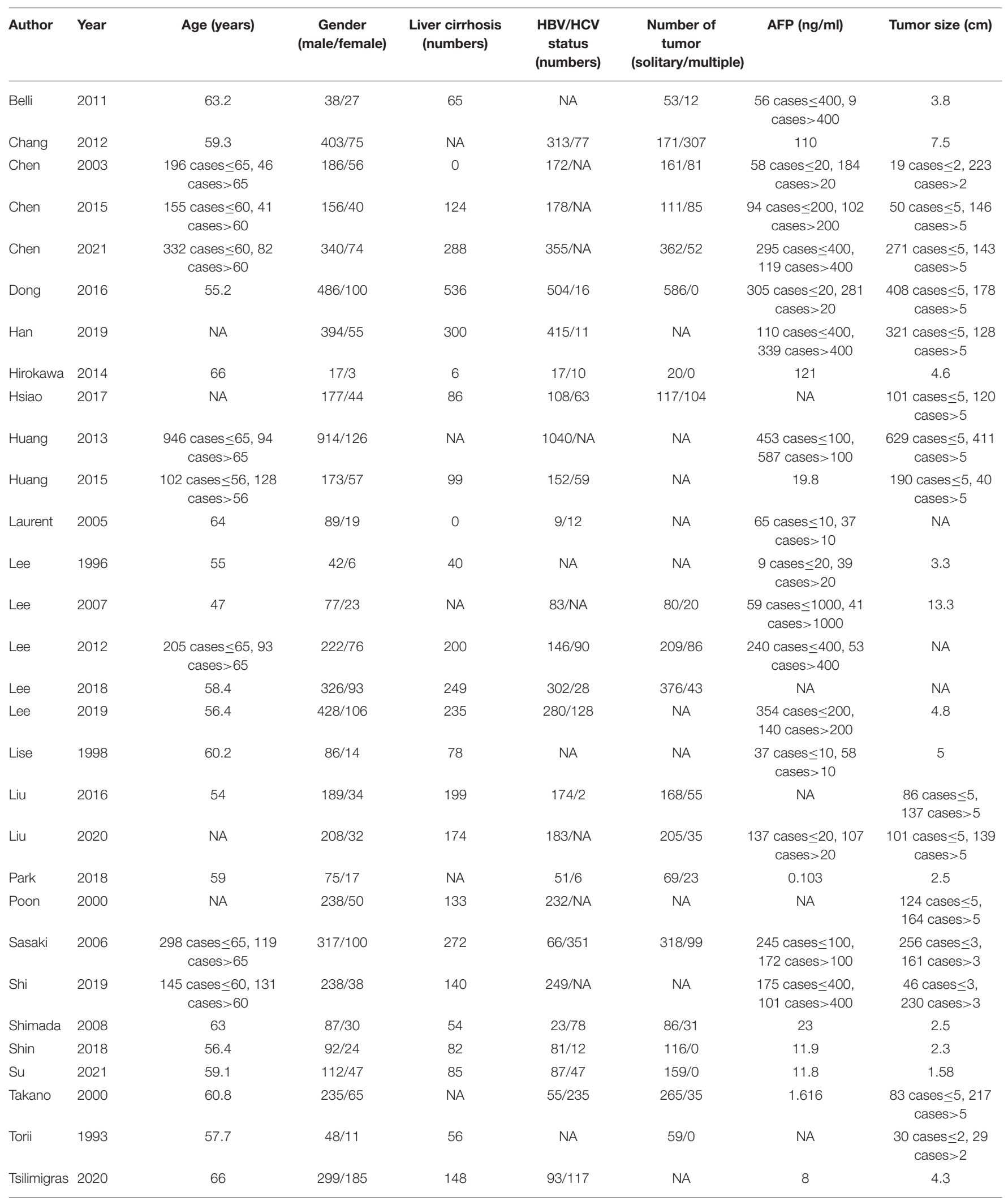


TABLE 1-2 | Continued

\begin{tabular}{|c|c|c|c|c|c|c|c|c|}
\hline Author & Year & Age (years) & $\begin{array}{c}\text { Gender } \\
\text { (male/female) }\end{array}$ & $\begin{array}{l}\text { Liver cirrhosis } \\
\text { (numbers) }\end{array}$ & $\begin{array}{l}\text { HBV/HCV } \\
\text { status } \\
\text { (numbers) }\end{array}$ & $\begin{array}{c}\text { Number of } \\
\text { tumor } \\
\text { (solitary/multiple) }\end{array}$ & AFP (ng/ml) & Tumor size $(\mathrm{cm})$ \\
\hline Wang & 2010 & 50 & $380 / 58$ & NA & NA & $374 / 54$ & NA & $\begin{array}{c}108 \text { cases } \leq 5,272 \\
\text { cases }>5\end{array}$ \\
\hline Yang & 2014 & NA & $877 / 208$ & NA & 210/NA & NA & NA & NA \\
\hline Zeng & 2020 & 36 & $615 / 84$ & 355 & 699/NA & $565 / 134$ & $\begin{array}{c}141 \text { cases } \leq 10,558 \\
\text { cases }>10\end{array}$ & 5.8 \\
\hline Zhang & 2014 & 48.9 & $253 / 49$ & 253 & $302 / N A$ & $238 / 64$ & $\begin{array}{c}90 \text { cases } \leq 20,212 \\
\text { cases }>20\end{array}$ & $\begin{array}{c}120 \text { cases } \leq 5,182 \\
\text { cases }>5\end{array}$ \\
\hline Zhang & 2021 & 53.8 & $357 / 68$ & 260 & $376 / 2$ & $354 / 71$ & 54.4 & 3.5 \\
\hline Zhou & 2020 & NA & $278 / 31$ & 170 & $274 / \mathrm{NA}$ & $228 / 81$ & $\begin{array}{l}203 \text { cases } \leq 400 \\
106 \text { cases }>400\end{array}$ & NA \\
\hline Zhou & 2021 & $\begin{array}{c}683 \text { cases } \leq 60,134 \\
\text { cases }>60\end{array}$ & $695 / 122$ & 360 & 713/NA & NA & $\begin{array}{l}452 \text { cases } \leq 400 \\
365 \text { cases }>400\end{array}$ & $\begin{array}{c}272 \text { cases } \leq 5,545 \\
\text { cases }>5\end{array}$ \\
\hline
\end{tabular}

$N A$, not available; $H B V$, hepatitis $B$ virus; $H C V$, hepatitis $C$ virus.

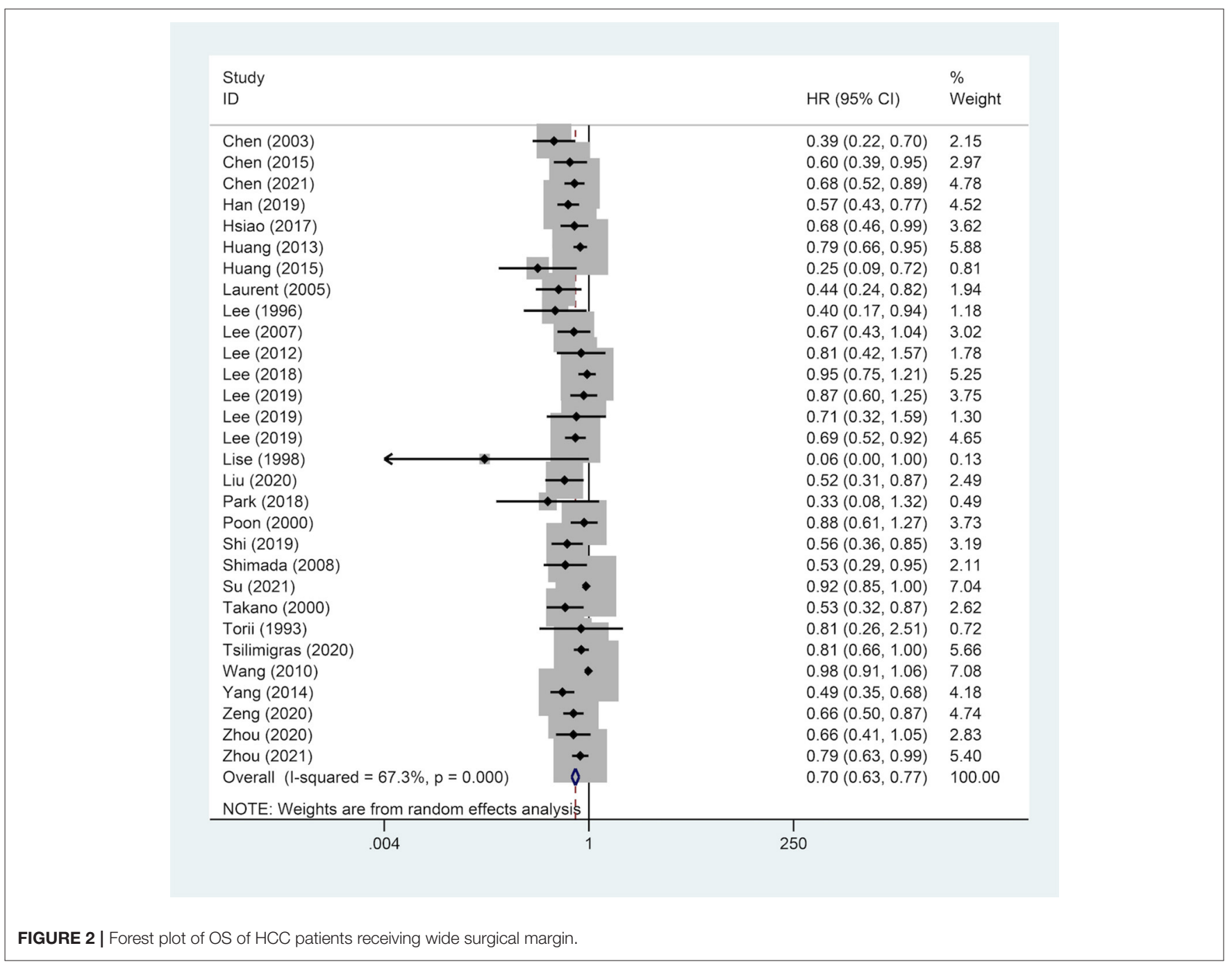


TABLE 2 | Subgroup analysis of the resection margin on the prognosis of patients with HCC.

\begin{tabular}{|c|c|c|c|c|c|c|}
\hline & \multicolumn{3}{|c|}{ Overall survival (OS) } & \multicolumn{3}{|c|}{ Disease-free survival (DFS) } \\
\hline & No. of studies & HR & $95 \% \mathrm{Cl}$ & No. of studies & HR & $95 \% \mathrm{Cl}$ \\
\hline 3-year survival & 5 & 0.67 & $0.54-0.82$ & 8 & 0.57 & $0.48-0.67$ \\
\hline 5-year survival & 23 & 0.70 & $0.63-0.79$ & 19 & 0.70 & $0.65-0.76$ \\
\hline Male & 18 & 0.68 & $0.59-0.78$ & 18 & 0.66 & $0.60-0.72$ \\
\hline Female & 9 & 0.75 & $0.64-0.89$ & 9 & 0.66 & $0.55-0.78$ \\
\hline China & 19 & 0.70 & $0.62-0.78$ & 17 & 0.67 & $0.62-0.72$ \\
\hline Non-Chinese Asian countries & 6 & 0.68 & $0.51-0.91$ & 4 & 0.64 & $0.46-0.88$ \\
\hline Western countries & 3 & 0.54 & $0.26-1.12$ & 4 & 0.45 & $0.30-0.66$ \\
\hline HBsAg positive & 10 & 0.71 & $0.65-0.78$ & 11 & 0.64 & $0.57-0.72$ \\
\hline HBsAg negative & 14 & 0.66 & $0.57-0.78$ & 14 & 0.70 & $0.64-0.77$ \\
\hline Single tumor & 9 & 0.80 & $0.71-0.92$ & 10 & 0.67 & $0.59-0.77$ \\
\hline Multiple tumors & 7 & 0.60 & $0.49-0.73$ & 7 & 0.66 & $0.57-0.78$ \\
\hline Liver cirrhosis & - & - & - & 4 & 0.71 & $0.60-0.84$ \\
\hline Non-liver cirrhosis & - & - & - & 18 & 0.64 & $0.58-0.71$ \\
\hline
\end{tabular}

HBsAg, hepatitis B surface antigen; HCC, hepatocellular carcinoma; HR, hazard ratio; Cl, confidence interval.

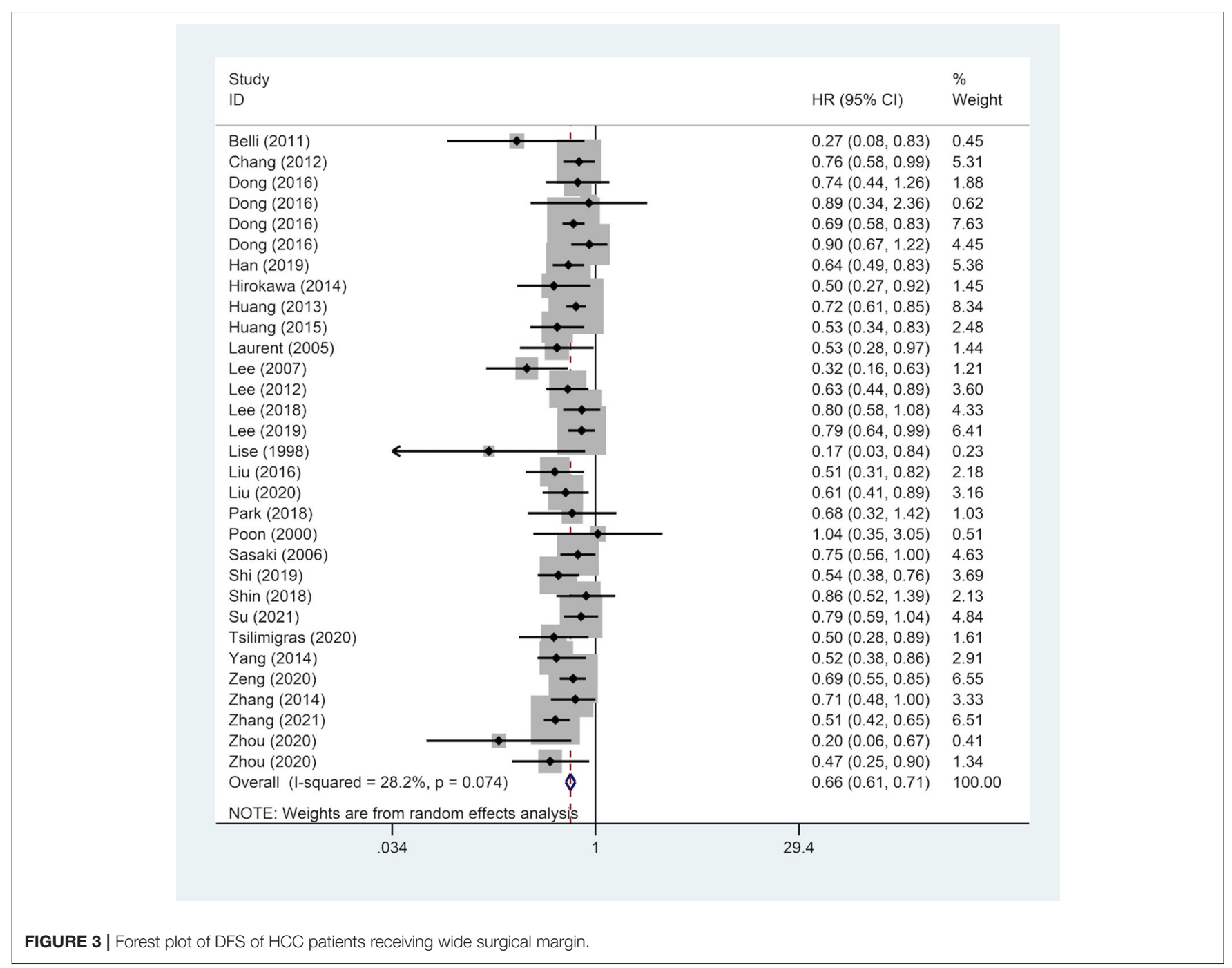


did not prolong the OS of patients compared to a narrow surgical margin. This is potentially attributed to the inclusion of a small number of studies (five articles).

No consensus has been reached in academia on whether gender is an independent risk factor for the prognosis of HCC patients after hepatectomy (45). Although there is no direct evidence that gender is a risk factor for HCC prognosis, men have higher smoking rates, alcohol consumption rates, and tumor burden than women (46). A different study found that women have a better long-term prognosis than men, but without statistical difference among patients with HCC lesions maximum size $<3 \mathrm{~cm}$ or with solitary HCC (47).

Notably, regional factors were also considered in subgroup analysis. The etiology of HCC in different regions is remarkably different. Asian countries, specifically East Asia are dominated by viral hepatitis, whereas HCC etiology in Western countries is mostly related to alcohol (48). Subgroup analyses revealed that despite HCC patients with/without hepatitis B virus (HBV) and liver cirrhosis, a wide surgical margin prolonged the prognosis of patients than a narrow surgical margin. HBV-liver cirrhosisHCC progression is a vital approach for HCC occurrence. High HBsAg level, lack of antiviral treatment, severe liver cirrhosis are risk factors affecting this process (49-51). However, in single or multiple HCC populations, the wide surgical margin group still yields a better prognosis than the narrow surgical margin group. Nevertheless, a study on a patients with solitary HCC lesions revealed that a wide surgical margin was not a prognostic factor. However, after propensity score matching (PSM), a wide surgical margin still prolongs the prognosis of patients (44). This is possibly because PSM could reduce the confounding bias of OBS and improve the research efficacy by omitting the unmatched study subjects.

Microvascular invasion (MVI) is the presence of tumor emboli in vascular spaces rowed by endothelial cells from the tumor capsule into the liver parenchyma (either hepatic vein or portal vein branches) (52). Based on the distribution and number of MVI, MVI is classified into the following grades, M0: no MVI; M1 (low risk): MVI $<5$ and the distance from adjacent liver tissues $\leq 1 \mathrm{~cm}$; and $M 2$ (high risk): MVI $>5$ or the distance from adjacent liver tissues $>1 \mathrm{~cm}$ (53). Researchers attempted to develop a preoperative model integrating laboratory examinations and imaging examinations to predict MVI. However, its accuracy requires additional validation by large-scale prospective multi-center studies (54). At present, MVI can only be diagnosed by postoperative histopathological examination; this significantly limits the application of MVI in guiding diagnosis and treatment. From MVI to macrovascular invasion, the malignant degree of HCC cells gradually increases and destroys the surrounding tissues; the chance of radical surgery is lost if a macrovascular invasion is formed (55). Therefore, effective surgical plans and postoperative adjuvant treatment can be adopted if timely interventions are implemented at the MVI stage of HCC. This thus minimizes metastasis and HCC recurrence as well as significantly improves the prognosis of patients.

To survive and metastasize, cancer cells must evade the immune system. After cancer cells invade the bloodstream, the classic hematological mechanism believes that platelets, leukocytes, and endothelial cells mediate the related process of metastasis and recurrence (56). New research indicates that MVI provides another path for HCC recurrence and metastasis; besides, HCC cell clusters obtain endothelial coating by protruding into the vessels. This enables evasion of the immune surveillance mechanism and thereby preventing the activation of the coagulation cascade (57-60). Thus, if a liver resection with a narrower surgical margin is performed on patients, theoretically, the residual micrometastasis increases the risk of recurrence (37). Besides, $90 \%$ of MVI occurs in the range narrower than $1 \mathrm{~cm}$ from the edge of the tumor. If a wider margin is achieved, the incidence of MVI can be reduced, hence significantly preventing tumor recurrence and metastasis (61). However, due to data unavailability, we were unable to analyze the influence of MVI on the results in subgroup analysis. On the other hand, the liver status may be another mechanism of the prognostic influence of the resection margin. Patients who received a wide resection margin tend to have better liver reserves than patients who received a narrow resection margin. Therefore, compared with the narrow surgical margin group, the wide surgical margin group could achieve better OS and DFS.

The surgical margin should however not be blindly enlarged for preventing the recurrence and metastasis of HCC after surgery. Because of the excessively wide surgical margin, more normal liver parenchyma will be removed, causing serious postoperative complications including liver failure, and eventually death $(8,9,11,12)$. Poon et al. (12) revealed that the relatively healthy liver parenchyma should not be sacrificed for obtaining the wider margin, particularly in cirrhotic patients with limited hepatic functional reserves. Another study (25) showed that a wide surgical margin did not improve the OS of patients compared to a narrow surgical margin. This was because of different baselines of the study group and the control group. This was largely reflected in liver cirrhosis, large and multiple tumors.

Previous research evaluated the relationship between surgical margins and prognosis by systematic review and meta-analysis $(62,63)$. The findings (62) are inconsistent with this metaanalysis and suggests that prognostic benefits are not achieved in patients receiving a resection margin $\geq 1 \mathrm{~cm}$. A small number of articles ( 5 articles) included a potential reason. The study by Zhong et al. (63) lacked sensitivity analysis, therefore, the reliability and stability of its findings are uncertain. Yet, its results were consistent with this paper's findings. However, it had its limitations. Primarily, although the number of included studies is more than that of previous studies, it is still a relatively small amount when compared to the number of studies in our article (37 articles vs. 7 articles). Besides, subgroup analysis was not performed by Zhong et al. (63). It, therefore, remains unknown whether the conclusion (the prognostic benefit of a wide surgical margin) is affected by other factors.

Our study has worth-mentioning limitations. Firstly, because of the limited number of related studies, comprehensive analysis of different resection margin width could not be performed. Secondly, the study population is from Asia, therefore the results cannot be directly applied to the population in Western countries. Thirdly, most of the included literature is 
retrospective, thereby hinting a possibility of the potential risk of information bias. Fourthly, because of the non-availability of relevant data, we were unable to perform additional subgroup analyses including MVI and kind of resection (anatomical vs. non-anatomical).

\section{CONCLUSION}

In conclusion, our meta-analysis revealed that a wide surgical margin $(\geq 1 \mathrm{~cm})$ potentially prolongs the long-term prognosis of HCC patients than a narrow surgical margin $(<1 \mathrm{~cm})$. This metaanalysis conducted various subgroup analyses, and the results remained consistent across most factors of median follow-up time, gender, country, hepatitis B surface antigen status, tumor number, and liver cirrhosis.

\section{DATA AVAILABILITY STATEMENT}

The original contributions presented in the study are included in the article/Supplementary Material, further inquiries can be directed to the corresponding author.

\section{REFERENCES}

1. Torre LA, Bray F, Siegel RL, Ferlay J, Lortet-Tieulent J, Jemal A. Global cancer statistics, 2012. CA Cancer J Clin. (2015) 65:87-108. doi: 10.3322/caac.21262

2. Siegel RL, Miller KD, Jemal A. Cancer statistics, 2015. CA Cancer J Clin. (2015) 65:5-29. doi: 10.3322/caac. 21254

3. Tabrizian P, Jibara G, Shrager B, Schwartz M, Roayaie S. Recurrence of hepatocellular cancer after resection: patterns, treatments, and prognosis. Ann Surg. (2015) 261:947-55. doi: 10.1097/SLA.0000000000000710

4. Chen B, Shen S, Wu J, Hua Y, Kuang M, Li S, et al. CISD2 associated with proliferation indicates negative prognosis in patients with hepatocellular carcinoma. Int J Clin Exp Pathol. (2015) 8:13725-38.

5. Huang WJ, Jeng YM, Lai HS, Sheu FY, Lai PL, Yuan RH. Tumor size is a major determinant of prognosis of resected stage I hepatocellular carcinoma. Langenbecks Arch Surg. (2015) 400:725-34. doi: 10.1007/s00423-015-1329-4

6. Hermanek P, Wittekind C. The pathologist and the residual tumor (R) classification. Pathol Res Pract. (1994) 190:115-23. doi: 10.1016/S0344-0338(11)80700-4

7. Lee JC, Cheng CH, Wang YC, Wu TH, Lee CF, Wu TJ, et al. Clinical relevance of alpha-fetoprotein in determining resection margin for hepatocellular carcinoma. Medicine. (2019) 98:e14827. doi: 10.1097/MD.0000000000014827

8. Madkhali AA, Fadel ZT, Aljiffry MM, Hassanain MM. Surgical treatment for hepatocellular carcinoma. Saudi J Gastroenterol. (2015) 21:11-7. doi: 10.4103/1319-3767.151216

9. Du ZG, Li B, Wei YG, Yin J, Feng X, Chen X. A new scoring system for assessment of liver function after successful hepatectomy in patients with hepatocellular carcinoma. Hepatobiliary Pancreat Dis Int. (2011) 10:265-9. doi: 10.1016/S1499-3872(11)60044-1

10. Chen MF, Tsai HP, Jeng LB, Lee WC, Yeh CN, Yu MC, Hung CM. Prognostic factors after resection for hepatocellular carcinoma in noncirrhotic livers: univariate and multivariate analysis. World J Surg. (2003) 27:443-7. doi: 10.1007/s00268-002-6708-7

11. Lee KT, Wang SN, Su RW, Chen HY, Shi HY, Ker CG, et al. Is wider surgical margin justified for better clinical outcomes in patients with resectable hepatocellular carcinoma? J Formos Med Assoc. (2012) 111:160-70. doi: 10.1016/j.jfma.2011.02.002

12. Poon RT, Fan ST, Ng IO, Wong J. Significance of resection margin in hepatectomy for hepatocellular carcinoma: a critical reappraisal. Ann Surg. (2000) 231:544-51. doi: 10.1097/00000658-200004000-00014

\section{AUTHOR CONTRIBUTIONS}

JZ designed the research process. JX and YL searched the database for corresponding articles and drafted the meta-analysis. JH extracted useful information from the articles above. YS used statistical software for analysis. YH polished this article. All authors had read and approved the manuscript and ensured that this was the case.

\section{SUPPLEMENTARY MATERIAL}

The Supplementary Material for this article can be found online at: https://www.frontiersin.org/articles/10.3389/fsurg. 2022.810479/full\#supplementary-material

Supplementary Figure 1 | Sensitivity analysis of OS for HCC patients receiving wide surgical margin.

Supplementary Figure 2 | Sensitivity analysis of DFS for HCC patients receiving wide surgical margin.

Supplementary Table 1 | Quality assessment of studies included.

13. Moher D, Liberati A, Tetzlaff J, Altman DG. Preferred reporting items for systematic reviews and meta-analyses: the PRISMA statement. BMJ. (2009) 339:b2535. doi: 10.1136/bmj.b2535

14. Belli G, Fantini C, Belli A, Limongelli P. Laparoscopic liver resection for hepatocellular carcinoma in cirrhosis: long-term outcomes. Dig Surg. (2011) 28:134-40. doi: 10.1159/000323824

15. Chang WT, Kao WY, Chau GY, Su CW, Lei HJ, Wu JC, et al. Hepatic resection can provide long-term survival of patients with non-early-stage hepatocellular carcinoma: extending the indication for resection? Surgery. (2012) 152:809-20. doi: 10.1016/j.surg.2012.03.024

16. Chen ZH, Zhang XP, Feng JK, Li LQ, Zhang F, Hu YR, Zhong CQ, et al. Actual long-term survival in hepatocellular carcinoma patients with microvascular invasion: a multicenter study from China. Hepatol Int. (2021) 15:642-50. doi: 10.1007/s12072-021-10174-x

17. Dong S, Wang Z, Wu L, Qu Z. Effect of surgical margin in R0 hepatectomy on recurrence-free survival of patients with solitary hepatocellular carcinomas without macroscopic vascular invasion. Medicine. (2016) 95:e5251. doi: 10.1097/MD.0000000000005251

18. Han J, Li ZL, Xing H, Wu H, Zhu P, Lau WY, et al. The impact of resection margin and microvascular invasion on long-term prognosis after curative resection of hepatocellular carcinoma: a multi-institutional study. HPB. (2019) 21:962-71. doi: 10.1016/j.hpb.2018.11.005

19. Hirokawa F, Hayashi M, Miyamoto Y, Asakuma M, Shimizu T, Komeda $\mathrm{K}$, et al. Outcomes and predictors of microvascular invasion of solitary hepatocellular carcinoma. Hepatol Res. (2014) 44:846-53. doi: 10.1111/hepr.12196

20. Hsiao JH, Tsai CC, Liang TJ, Chiang CL, Liang HL, Chen IS, et al. Adjuvant hepatic arterial infusion chemotherapy is beneficial for selective patients with hepatocellular carcinoma undergoing surgical treatment. Int J Surg. (2017) 45:35-41. doi: 10.1016/j.ijsu.2017.07.071

21. Huang G, Yang Y, Shen F, Pan ZY, Fu SY, Lau WY, et al. Early viral suppression predicts good postoperative survivals in patients with hepatocellular carcinoma with a high baseline HBV-DNA load. Ann Surg Oncol. (2013) 20:1482-90. doi: 10.1245/s10434-0122803-7

22. Laurent C, Blanc JF, Nobili S, Sa Cunha A, le Bail B, Bioulac-Sage P, et al. Prognostic factors and longterm survival after hepatic resection for hepatocellular carcinoma originating from noncirrhotic liver. J Am Coll Surg. (2005) 201:656-62. doi: 10.1016/j.jamcollsurg.2005.05.027 
23. Lee CS, Sheu JC, Wang M, Hsu HC. Long-term outcome after surgery for asymptomatic small hepatocellular carcinoma. Br J Surg. (1996) 83:330-3. doi: $10.1002 /$ bjs. 1800830310

24. Lee SG, Hwang S, Jung JP, Lee YJ, Kim KH, Ahn CS. Outcome of patients with huge hepatocellular carcinoma after primary resection and treatment of recurrent lesions. Br J Surg. (2007) 94:320-6. doi: 10.1002/bjs.5622

25. Lee W, Han HS, Ahn S, Yoon YS, Cho JY, Choi Y. Correlation between resection margin and disease recurrence with a restricted cubic spline model in patients with resected hepatocellular carcinoma. Dig Surg. (2018) 35:52031. doi: 10.1159/000485805

26. Lise M, Bacchetti S, Da Pian P, Nitti D, Pilati PL, Pigato P. Prognostic factors affecting long term outcome after liver resection for hepatocellular carcinoma: results in a series of 100 Italian patients. Cancer. (1998) 82:1028-36.

27. Liu L, Shui Y, Yu Q, Guo Y, Zhang L, Zhou X, et al. Narrow-margin hepatectomy resulted in higher recurrence and lower overall survival for R0 resection hepatocellular carcinoma. Front Oncol. (2020) 10:610636. doi: $10.3389 /$ fonc.2020.610636

28. Liu Y, Wang ZX, Cao Y, Zhang G, Chen WB, Jiang CP. Preoperative inflammation-based markers predict early and late recurrence of hepatocellular carcinoma after curative hepatectomy. Hepatobiliary Pancreat Dis Int. (2016) 15:266-74. doi: 10.1016/S1499-3872(16)60094-2

29. Park JH, Kim DH, Kim SH, Kim MY, Baik SK, Hong IS. The clinical implications of liver resection margin size in patients with hepatocellular carcinoma in terms of positron emission tomography positivity. World J Surg. (2018) 42:1514-22. doi: 10.1007/s00268-017-4275-1

30. Sasaki Y, Yamada T, Tanaka H, Ohigashi H, Eguchi H, Yano M, et al. Risk of recurrence in a long-term follow-up after surgery in 417 patients with hepatitis B- or hepatitis C-related hepatocellular carcinoma. Ann Surg. (2006) 244:771-80. doi: 10.1097/01.sla.0000225126.56483.b3

31. Shi F, Zhou Z, Huang X, Liu Q, Lin A. Is anatomical resection necessary for early hepatocellular carcinoma? A single institution retrospective experience. Future Oncol. (2019) 15:2041-51. doi: 10.2217/fon-2019-0117

32. Shimada K, Sakamoto Y, Esaki M, Kosuge T. Role of the width of the surgical margin in a hepatectomy for small hepatocellular carcinomas eligible for percutaneous local ablative therapy. Am J Surg. (2008) 195:775-81. doi: 10.1016/j.amjsurg.2007.06.033

33. Shin S, Kim TS, Lee JW, Ahn KS, Kim YH, Kang KJ. Is the anatomical resection necessary for single hepatocellular carcinoma smaller than $3 \mathrm{~cm}$ ?: single-center experience of liver resection for a small HCC. Ann Hepatobiliary Pancreat Surg. (2018) 22:326-34. doi: 10.14701/ahbps.2018.22.4.326

34. Su CM, Chou CC, Yang TH, Lin YJ. Comparison of anatomic and nonanatomic resections for very early-stage hepatocellular carcinoma: The importance of surgical resection margin width in non-anatomic resection. Surg Oncol. (2021) 36:15-22. doi: 10.1016/j.suronc.2020.11.009

35. Takano S, Oishi H, Kono S, Kawakami S, Nakamura M, Kubota N, et al. Retrospective analysis of type of hepatic resection for hepatocellular carcinoma. Br J Surg. (2000) 87:65-70. doi: 10.1046/j.1365-2168.2000.01308.x

36. Torii A, Nonami T, Harada A, Yasui M, Nakao A, Takagi H. Extent of hepatic resection as a prognostic factor for small, solitary hepatocellular carcinomas. $J$ Surg Oncol. (1993) 54:13-7. doi: 10.1002/jso.2930540106

37. Tsilimigras DI, Sahara K, Moris D, Hyer JM, Paredes AZ, Bagante F, et al. Effect of surgical margin width on patterns of recurrence among patients undergoing R0 hepatectomy for T1 hepatocellular carcinoma: an international multi-institutional analysis. J Gastrointest Surg. (2020) 24:155260. doi: 10.1007/s11605-019-04275-0

38. Wang J, Xu LB, Liu C, Pang HW, Chen YJ, Ou QJ. Prognostic factors and outcome of 438 Chinese patients with hepatocellular carcinoma underwent partial hepatectomy in a single center. World J Surg. (2010) 34:2434-41. doi: 10.1007/s00268-010-0664-4

39. Yang J, Li C, Wen TF, Yan LN, Li B, Wang WT, et al. Is hepatectomy for huge hepatocellular carcinoma ( $\geq 10 \mathrm{~cm}$ in diameter) safe and effective? A single-center experience. Asian Pac J Cancer Prev. (2014) 15:7069-77. doi: 10.7314/APJCP.2014.15.17.7069

40. Zeng J, Lin K, Liu H, Huang Y, Guo P, Zeng Y, et al. prognosis factors of young patients undergoing curative resection for hepatitis B virus-related hepatocellular carcinoma: a multicenter study. Cancer Manag Res. (2020) 12:6597-606. doi: 10.2147/CMAR.S261368
41. Zhang H, Liu F, Wen N, Li B, Wei Y. Patterns, timing, and predictors of recurrence after laparoscopic liver resection for hepatocellular carcinoma: results from a high-volume HPB center. Surg Endosc. (2022) 36:1215-23. doi: 10.1007/s00464-021-08390-5

42. Zhang XF, Wei T, Liu XM, Liu C, Lv Y. Impact of cigarette smoking on outcome of hepatocellular carcinoma after surgery in patients with hepatitis B. PLoS ONE. (2014) 9:e85077. doi: 10.1371/journal.pone.0085077

43. Zhou KQ, Sun YF, Cheng JW, Du M, Ji Y, Wang PX, et al. Effect of surgical margin on recurrence based on preoperative circulating tumor cell status in hepatocellular carcinoma. EBioMedicine. (2020) 62:103107. doi: 10.1016/j.ebiom.2020.103107

44. Zhou Z, Qi L, Mo Q, Liu Y, Zhou X, Zhou Z, et al. Effect of surgical margin on postoperative prognosis in patients with solitary hepatocellular carcinoma: a propensity score matching analysis. J Cancer. (2021) 12:4455-62. doi: $10.7150 /$ jca. 57896

45. El-Serag HB. Epidemiology of viral hepatitis and hepatocellular carcinoma. Gastroenterology. (2012) 142:1264-73.e1261. doi: 10.1053/j.gastro.2011.12.061

46. Ladenheim MR, Kim NG, Nguyen P, Le A, Stefanick ML, Garcia G, et al. Sex differences in disease presentation, treatment and clinical outcomes of patients with hepatocellular carcinoma: a single-centre cohort study. BMJ Open Gastroenterol. (2016) 3:e000107. doi: 10.1136/bmjgast-2016-000107

47. Dohmen $\mathrm{K}$, Shigematsu H, Irie K, Ishibashi H. Longer survival in female than male with hepatocellular carcinoma. J Gastroenterol Hepatol. (2003) 18:267-72. doi: 10.1046/j.1440-1746.2003.02936.x

48. Akinyemiju T, Abera S, Ahmed M, Alam N, Alemayohu MA, Allen C, et al. the burden of primary liver cancer and underlying etiologies from 1990 to 2015 at the global, regional, and national level: results from the global burden of disease study 2015. JAMA Oncol. (2017) 3:1683-91. doi: 10.1001/jamaoncol.2017.3055

49. Chien J, Liu J, Lee MH, Jen CL, Batrla-Utermann R, Lu SN, et al. Risk and predictors of hepatocellular carcinoma for chronic hepatitis B patients with newly developed cirrhosis. J Gastroenterol Hepatol. (2016) 31:1971-7. doi: $10.1111 /$ jgh. 13422

50. Bonino F, Oliveri F, Colombatto P, Brunetto MR. Impact of interferon-alpha therapy on the development of hepatocellular carcinoma in patients with liver cirrhosis: results of an international survey. J Viral Hepat. (1997) 4(Suppl. 2):79-82. doi: 10.1111/j.1365-2893.1997.tb00183.x

51. Shim JJ, Oh CH, Kim JW, Lee CK, Kim BH. Liver cirrhosis stages and the incidence of hepatocellular carcinoma in chronic hepatitis B patients receiving antiviral therapy. Scand J Gastroenterol. (2017) 52:1029-36. doi: 10.1080/00365521.2017.1335773

52. Poté N, Cauchy F, Albuquerque M, Voitot H, Belghiti J, Castera L, et al. Performance of PIVKA-II for early hepatocellular carcinoma diagnosis and prediction of microvascular invasion. J Hepatol. (2015) 62:848-54. doi: 10.1016/j.jhep.2014.11.005

53. Cong WM, Bu H, Chen J, Dong H, Zhu YY, Feng LH, et al. Practice guidelines for the pathological diagnosis of primary liver cancer: 2015 update. World $J$ Gastroenterol. (2016) 22:9279-87. doi: 10.3748/wjg.v22.i42.9279

54. Lei Z, Li J, Wu D, Xia Y, Wang Q, Si A, et al. Nomogram for preoperative estimation of microvascular invasion risk in hepatitis B virus-related hepatocellular carcinoma within the milan criteria. JAMA Surg. (2016) 151:356-63. doi: 10.1001/jamasurg.2015.4257

55. EASL-EORTC clinical practice guidelines: management of hepatocellular carcinoma. J Hepatol. (2012) 56:908-43. doi: 10.1016/j.jhep.2011.12.001

56. Kappelmayer J, Nagy B Jr. The interaction of selectins and PSGL-1 as a key component in thrombus formation and cancer progression. Biomed Res Int. (2017) 2017:6138145. doi: 10.1155/2017/6138145

57. Ding T, Xu J, Zhang Y, Guo RP, Wu WC, Zhang SD, et al. Endotheliumcoated tumor clusters are associated with poor prognosis and micrometastasis of hepatocellular carcinoma after resection. Cancer. (2011) 117:4878-89. doi: $10.1002 /$ cncr.26137

58. Mitsunobu M, Toyosaka A, Oriyama T, Okamoto E, Nakao N. Intrahepatic metastases in hepatocellular carcinoma: the role of the portal vein as an efferent vessel. Clin Exp Metastasis. (1996) 14:520-9. doi: 10.1007/BF00115112

59. Rodríguez-Perálvarez M, Luong TV, Andreana L, Meyer T, Dhillon AP, Burroughs AK. A systematic review of microvascular invasion in 
hepatocellular carcinoma: diagnostic and prognostic variability. Ann Surg Oncol. (2013) 20:325-39. doi: 10.1245/s10434-012-2513-1

60. Sugino T, Yamaguchi T, Hoshi N, Kusakabe T, Ogura G, Goodison $\mathrm{S}$, et al. Sinusoidal tumor angiogenesis is a key component in hepatocellular carcinoma metastasis. Clin Exp Metastasis. (2008) 25:835-41. doi: 10.1007/s10585-008-9199-6

61. Feng LH, Dong H, Lau WY, Yu H, Zhu YY, Zhao Y, et al. Novel microvascular invasion-based prognostic nomograms to predict survival outcomes in patients after R0 resection for hepatocellular carcinoma. J Cancer Res Clin Oncol. (2017) 143:293-303. doi: 10.1007/s00432-0162286-1

62. Tang YH, Wen TF, Chen X. Resection margin in hepatectomy for hepatocellular carcinoma: a systematic review. Hepatogastroenterology. (2012) 59:1393-7. doi: 10.5754/hge10600

63. Zhong FP, Zhang YJ, Liu Y, Zou SB. Prognostic impact of surgical margin in patients with hepatocellular carcinoma: a metaanalysis. Medicine. (2017) 96:e8043. doi: 10.1097/MD.000000000000 08043
Conflict of Interest: The authors declare that the research was conducted in the absence of any commercial or financial relationships that could be construed as a potential conflict of interest.

Publisher's Note: All claims expressed in this article are solely those of the authors and do not necessarily represent those of their affiliated organizations, or those of the publisher, the editors and the reviewers. Any product that may be evaluated in this article, or claim that may be made by its manufacturer, is not guaranteed or endorsed by the publisher.

Copyright (c) $2022 \mathrm{Lin}, \mathrm{Xu}$, Hong, Si, He and Zhang. This is an open-access article distributed under the terms of the Creative Commons Attribution License (CC BY). The use, distribution or reproduction in other forums is permitted, provided the original author(s) and the copyright owner(s) are credited and that the original publication in this journal is cited, in accordance with accepted academic practice. No use, distribution or reproduction is permitted which does not comply with these terms. 